\title{
Determinants of Postgraduate Students' Choices of Speciality
}

\author{
Bikash Shrestha, ${ }^{1}$ Yagya Raj Pokhrel, ${ }^{2}$ Katrina Butterworth ${ }^{2}$ \\ 'Grande International Hospital, ${ }^{2}$ Patan Academy of Health Sciences, Patan Hospital, Nepal.
}

\section{ABSTRACT}

Introduction: Postgraduate specialization is perceived as essential for success with high competition for enrolment. The reasons how medical students choose their postgraduate specialty are complex. Understanding the factors that influence career choice helps in workforce planning. So, we tried to identify the specialty preferred by postgraduate students and the factors that influenced these choices in a post graduate institution.

Methods: A cross-sectional observational study was conducted in National Academy of Medical Sciences. All the postgraduate students of batch 2011 AD were enrolled for the study. The responses were rated on a five point Likert scale.

Results: Significant gender preference was observed in specialties. General Surgery, Internal Medicine and Orthopedics were chosen by male students (P-Values, respectively, 0.001, 0.033 and 0.000) while Obstetrics and Gynecology and Ophthalmology being chosen by female students (P-Values, respectively, 0.000 and 0.006). Significant difference was observed between male and female student responses to the factor - scope in future ( $\mathrm{P}$ - value 0.042), between married and unmarried students to the factor - workload flexibility ( $\mathrm{P}$ - value 0.011$)$, students who tried to go abroad versus who didn't, for the factor - Illness of self/family/friend ( $\mathrm{P}$ - value 0.016), and between those who worked in rural area versus those who didn't, to the factor - Influence of friends/ seniors (P - value 0.038).

Conclusions: Various factors affect the choices for preferred specialty. Policy makers should look at the needs of the nation, and ensure that specialty postgraduate education programs reflect those needs.

Keywords: career choices; likert scale; medical education; postgraduate specialty.

\section{INTRODUCTION}

Post-graduate specialization is perceived as essential for success, with high competition for post graduate seats, ${ }^{1}$ especially in clinical specialties in Nepal as well. Medical graduates can be seen as multi-potent 'stem doctors'; specialization turns them into fullydifferentiated specialists. ${ }^{2}$ The clinical experiences along with sociocultural values, ${ }^{4}$ have a major impact on the decision about education after undergraduate studies. ${ }^{5}$
The reasons why medical students choose their careers are complex, ${ }^{9}$ and still remain partially understood. ${ }^{10}$ Most of these studies done are on the undergraduate students who have less clinical experience so; most of the choices made are liable to change as they proceed

Correspondence: Dr. Bikash Shrestha, General Practice, Grande International Hospital, Kathmandu, Nepal. Email: shrestha811@ gmail.com, Phone: +977-9841486393. 
with their medical education. ${ }^{12}$ Understanding the factors that influence career decisions may help in workforce planning in different specialties. ${ }^{13}$

We conducted this study to identify the specialty preferred by postgraduate students, and the factors that influenced these choices, at National Academy of Medical Sciences (NAMS).

\section{METHODS}

The study is a cross-sectional; hospital based quantitative observational study done in National Academy of Medical Sciences (NAMS), Bir Hospital, Kathmandu. Bir Hospital, the nation's oldest hospital established in the year $1889 \mathrm{AD}$, is the only tertiary referral center in the country which provides free service. ${ }^{18}$

The study proposal and questionnaire were submitted to Institutional Review Board, NAMS and ethical approval was obtained to conduct the study. Duration of study was from January 2012 to July 2014 AD.

All the postgraduate students of batch 2011 were included in the study. Those who failed to respond were excluded from the study. They were provided with structured questionnaire set. The questionnaire was based on previous studies conducted among medical students in Nepal, ${ }^{12}$ and among medical students in India. ${ }^{13}$ The students were explained about the study, an oral consent was taken.

The first part of the questionnaire comprised of variables regarding demographic details and list of medical specialties from which the students had to select the first 3 specialties which were chosen when they filled the entrance form. In the second part of the questionnaire, students were asked to select the degree to which the 20 factors influenced their decision to choose the subject in which they got enrolled. The responses were rated on a five-point Likert scale ranging from 1 (No Significance) to 5 (Very High Significance). Data analysis was done using Epi Info 7 and Fisher Exact test was used for statistical analysis of Likert scale.

\section{RESULTS}

\section{Response rates and demographic characteristics}

Out of 94 postgraduate students in the year of 2011 AD of NAMS, 83 students responded to the questionnaire giving an overall response rate of $87.37 \%$. Three students did not take part in the study and 8 students failed to return the questionnaire. So, total 83 completed questionnaires were analyzed. Median age of the students was 30 years (mean $30.168, S D \pm 1.82$ ). Out of 60 male students $26(43.33 \%)$ and out of 23 female students, $13(56.52 \%)$ were married. Nineteen out of 83 were working as government doctors. Fifty-nine percent (49 out of 83) of the respondents worked in rural areas prior to starting their postgraduate studies. Nearly $37 \%$ of the respondents tried to go abroad (who tried to go or who went abroad but returned after they failed to continue their further studies) and eightyseven percent $(87 \%)$ of them thought that there should be career counseling before getting to the postgraduate program (Figure 2).
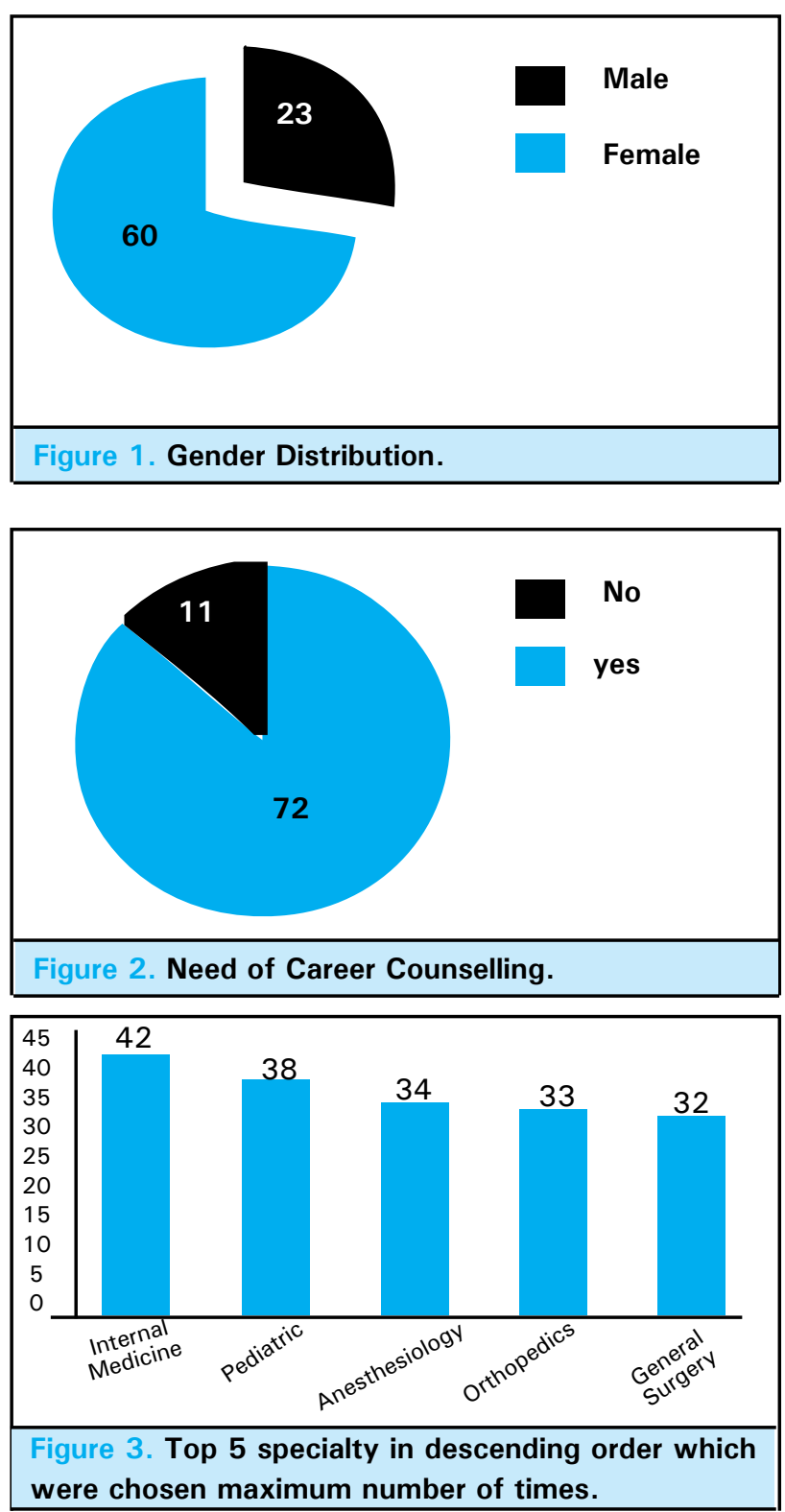

\section{Choice of medical specialty}

Twenty five students had a clear choice of specialty when they started MBBS and out of whom 13 (52\%) students changed their choice during the entrance exam of postgraduate study. In the total students enrolled, 
50 students out of 83 got the specialty which they had kept as the $1^{\text {st }}$ choice. The top 3 specialties ranked on the first choice were Internal medicine, General surgery and Orthopedics. Internal Medicine was the number one specialty chosen by maximum number of student maximum number of times. For the first choice the top subject chosen by female students was Gynecology and Obstetrics followed by Pediatrics. On the other hand, male students chose Internal Medicine, General surgery followed by Orthopedics as the top three subjects for the first choice (Table 1). Significant gender preference was observed in specialties, in which subjects like General Surgery, Internal Medicine and Orthopedics were being chosen by male students predominantly (P-Values, respectively, $0.001,0.033$ and 0.000 ) while Obstetrics and Gynecology and Ophthalmology being chosen by female students predominantly (P-Values, respectively, 0.000 and 0.006). Ninety-four percent of students were satisfied with the subject they chose, however 4 students said that they may change the subject depending on the financial position, sponsorship, family influences, status of self-health and working environment.

\begin{tabular}{|c|c|c|c|c|c|c|}
\hline \multirow[b]{2}{*}{ Specialty } & \multicolumn{2}{|c|}{ Male $(n=180)$} & \multicolumn{2}{|c|}{ Female $(n=69)$} & \multirow{2}{*}{ Chi-squared test } & \multirow[b]{2}{*}{ P-value } \\
\hline & Frequency & Percent & Frequency & Percent & & \\
\hline Anaesthesiology & 22 & 12.22 & 12 & 17.40 & 1.13 & 0.288 \\
\hline Dermatology & 6 & 3.33 & 2 & 2.90 & 0.30 & 0.867 \\
\hline Paediatrics & 24 & 13.33 & 14 & 20.30 & 1.87 & 0.172 \\
\hline General Practice & 9 & 5 & 0 & 0 & 3.50 & 0.059 \\
\hline General Surgery & 31 & 17.22 & 1 & 1.44 & 11.10 & 0.001 \\
\hline Internal Medicine & 36 & 20 & 6 & 8.70 & 4.55 & 0.033 \\
\hline $\begin{array}{l}\text { Obstetrics \& } \\
\text { Gynaecology }\end{array}$ & 5 & 2.78 & 12 & 17.40 & 16.70 & 0.000 \\
\hline Ophthalmology & 4 & 2.22 & 7 & 10.14 & 7.41 & 0.006 \\
\hline Orthopaedics & 33 & 18.33 & 0 & 0 & 14.60 & 0.000 \\
\hline Radiodiagnosis & 8 & 4.44 & 5 & 7.24 & 0.79 & 0.374 \\
\hline Pathology* & 0 & 0 & 2 & 2.90 & & \\
\hline ENT \& HNS* & 1 & 0.55 & 0 & 0 & & \\
\hline Psychiatry* & 0 & 0 & 1 & 1.44 & & \\
\hline Radiotherapy* & 1 & 0.55 & 1 & 1.44 & & \\
\hline Total & 180 & 100 & 69 & 100 & & \\
\hline
\end{tabular}

*Numbers too few for analysis

\begin{tabular}{|c|c|c|c|c|c|}
\hline \multirow[b]{2}{*}{$\begin{array}{l}\text { S. } \\
\text { No. }\end{array}$} & \multirow[b]{2}{*}{ Influencing Factors } & \multicolumn{2}{|c|}{ Sex } & \multicolumn{2}{|c|}{ Marital Status } \\
\hline & & $\begin{array}{c}\text { Fischer Exact } \\
\text { test }\end{array}$ & P - Value & $\begin{array}{c}\text { Fischer } \\
\text { Exact test }\end{array}$ & $P$-Value \\
\hline 1 & Personal Interest in the specialty & 3.9 & 0.763 & 1.8 & 0.64 \\
\hline 2 & Secure and having Scope in Future & 9.8 & 0.042 & 1.4 & 0.57 \\
\hline 3 & Reputation of specialty and Prestige & 2.2 & 0.576 & 1.8 & 0.126 \\
\hline 4 & Good Doctor Patient relationship & 2.7 & 0.651 & 2.7 & 0.857 \\
\hline 5 & Experiences during medical career & 1.3 & 0.103 & 1.6 & 0.833 \\
\hline 6 & Illness of self/ family/ friend & 2 & 0.094 & 6 & 0.36 \\
\hline 7 & Influence of Family & 1.2 & 0.519 & 1.5 & 0.754 \\
\hline 8 & Influence of friends/ seniors & 4.4 & 0.927 & 2.2 & 0.866 \\
\hline 9 & Influence of faculty / Role Model & 1.4 & 0.604 & 1.7 & 0.853 \\
\hline
\end{tabular}


Shrestha et al. Determinants of Postgraduate Students' Choices of Speciality

\begin{tabular}{|llcccc|}
10 & Desire to serve in rural / underserved area & 8.6 & 0.423 & 1.2 & 0.688 \\
11 & Work Load flexibility & 2 & 0.725 & 6.2 & 0.011 \\
12 & Wide range of patient problems & 1.2 & 0.495 & 1.9 & 0.817 \\
13 & Work Satisfaction & 4.6 & 0.519 & 1.6 & 0.311 \\
14 & Dislike direct interaction with patients & 1.7 & 0.463 & 1.3 & 0.525 \\
15 & Books/ Films & 2.5 & 0.618 & 1.3 & 0.544 \\
16 & Best available course(whatever you can qualify) & 3.2 & 0.902 & 7.1 & 0.519 \\
\hline
\end{tabular}

\begin{tabular}{|c|c|c|c|c|c|}
\hline \multirow[b]{2}{*}{ S. No. } & \multirow[b]{2}{*}{ Influencing Factors } & \multicolumn{2}{|c|}{ Oversea experience } & \multicolumn{2}{|c|}{ Working experience } \\
\hline & & $\begin{array}{c}\text { Fischer Exact } \\
\text { test }\end{array}$ & $P$ - Value & $\begin{array}{c}\text { Fischer Exact } \\
\text { test }\end{array}$ & $P$ - Value \\
\hline 1 & Personal Interest in the specialty & 1.7 & 0.55 & 2.1 & 0.114 \\
\hline 2 & Secure and having Scope in Future & 3.1 & 0.161 & 1.9 & 0.105 \\
\hline 3 & Reputation of specialty and Prestige & 1.5 & 0.582 & 3.9 & 0.227 \\
\hline 4 & Good Doctor Patient relationship & 4 & 0.928 & 1.1 & 0.074 \\
\hline 5 & Experiences during medical career & 1 & 0.634 & 1.3 & 0.756 \\
\hline 6 & Illness of self/ family/ friend & 1.9 & 0.016 & 1.3 & 0.569 \\
\hline 7 & Influence of Family & 2.9 & 0.954 & 6.5 & 0.447 \\
\hline 8 & Influence of friends/ seniors & 2.6 & 0.889 & 3.5 & 0.038 \\
\hline 9 & Influence of faculty / Role Model & 6.4 & 0.447 & 1.4 & 0.147 \\
\hline 10 & Desire to serve in rural / underserved area & 3.4 & 0.278 & 1 & 0.605 \\
\hline 11 & Work Load flexibility & 1 & 0.609 & 6.5 & 0.464 \\
\hline 12 & Wide range of patient problems & 1.6 & 0.727 & 6.4 & 0.069 \\
\hline 13 & Work Satisfaction & 2.1 & 0.351 & 1.2 & 0.23 \\
\hline 14 & Dislike direct interaction with patients & 1.6 & 0.552 & 8.1 & 0.356 \\
\hline 15 & Books/ Films & 3 & 0.81 & 6.5 & 0.317 \\
\hline 16 & Best available course(whatever you can qualify) & 1.5 & 0.752 & 7.2 & 0.087 \\
\hline
\end{tabular}

Factors affecting the choice of specialty

For most students the highly significant factors influencing choice of specialty for postgraduate studies were: Personal Interest in the specialty, Secure and having Scope in Future, Good Doctor Patient relationship, Workload flexibility, and Work Satisfaction. Factors like Reputation of specialty and Prestige, Influence of friends/ seniors and Wide range of patient problems had some significance. The Likert scores for the responses for influencing factors were analyzed for significance between the gender, marital status, oversea experience and experience of working in rural area (Tables 2 and 3 respectively). A statistically significant difference $(P<0.05)$ was observed between male and female student responses to the factor - secure and having scope in future ( $P$ - value 0.042). Male students were more affected by this factor. Likewise statistically significant difference was observed between married and unmarried students to the factor - workload flexibility (P - value 0.011) in which surprisingly unmarried students wanted to have more flexibility in workload. Analysis done for the students having oversea experience showed statistically significant difference for the factor - Illness of self/family/friend ( $P$ - value 0.016$)$ in which those who didn't go abroad were affected by this factor. Factor - Influence of friends/ seniors differed significantly $(P-$ value 0.038$)$ between those who worked in rural area versus those who didn't where those who worked in rural areas are influenced by this factor the most.

\section{DISCUSSION}

Many studies have been done regarding the choices of specialty and factors influencing them in undergraduate medical students and junior doctors, ${ }^{1-17}$ who have less experience regarding the clinical exposure and, most of the times choices made are temporary and are liable to change as their medical education continues. ${ }^{12}$ Similar 
result was seen in our study, among those who had specialty choice at the beginning of the MBBS, $52 \%$ has changed the specialty choice during the entrance of postgraduate study.

The most preferred specialty in our study was Internal Medicine which is similar to the results of the studies done in other countries. ${ }^{19-23}$ However, studies done in Jordan and Greece showed that students preferred surgical specialty most over medical, ${ }^{24,25}$ which was the $2^{\text {nd }}$ preferred specialty in our study. There may be several possible explanations for Internal Medicine to be the most preferred specialty. Still today, Internists are considered as "Doctors for consultation" who are always summoned for consulting cases with multiple co-morbidities. Next point for choosing Internal Medicine for postgraduate studies may be because it has more choices for super-specialization. ${ }^{2}$ Another explanation may be the increased awareness of the growing burden of chronic diseases (communicable as well as non-communicable). In our study general practice was one of the least preferred specialties. These results have been observed in other studies done in Nepal, ${ }^{12,17}$ and also in the western countries. ${ }^{26,27}$ It is clear that medical care can be best provided in the rural community by general practitioners as they can handle variety of cases including surgical, obstetrics and orthopaedic cases and they are also the doctors with good communication skills. ${ }^{6}$ A study done in Australia suggested that increasing the salary, opportunities for procedural and academic work would help to address the imbalance between specialists and the generalists. ${ }^{1}$ Likewise a study done in Nepal showed that the multiple factors from level of community awareness, career development to secure working environment should be addressed to retain general practitioners in the rural community. ${ }^{6}$ Policy makers should now be alert about the postgraduate training program and should know that it is not just running the program but, it has the direct relationship between health care provider and patients. They should look at the needs of the nation, and ensure that specialty postgraduate education programs reflect those needs.

In our study gender had a significant effect on preferring the certain specialty. Male participant predominantly chose Internal Medicine, General Surgery and Orthopaedics whereas female students chose Obstetrics \& Gynaecology and Ophthalmology predominantly. These results were consistent with studies done in various parts of the world. ${ }^{1-3,12}$ The possible reason behind male participants choosing Orthopaedics and General Surgery may be the result of cultural thinking that males are thought to be the gender with strong will power and daring to take strong decisions during the work. In contrast, though having busy schedules,
Obstetrics and Gynaecology are chosen by female. This may be the result of cultural and religious reasons, because women prefer to be treated by the female doctors which also holds true in our country.

Factors influencing the choices of preferred specialty are complex and decision making is affected by more than one factor most of the time. ${ }^{2}$ The factors which affected the most in choosing the specialty are variable: job satisfaction, personality and lifestyle of seniors, inspiration from teaching faculty, challenging nature of specialty, prestige of specialty, personal interest, financial status, serving the sick, career stability and income. ${ }^{1,2,12,28,29}$ In our study Personal Interest in the specialty, Secure and having Scope in Future, Good Doctor Patient relationship and Work Satisfaction were the highly significant factors which are similar to the study done in Nepal, ${ }^{12}$ except for workload flexibility which was highly significant in our study but not in the study done by Hayes and Shakya, ${ }^{12}$ whereas, IIIness of self/ family/ friend, Influence of Family, Influence of faculty / Role Model, Desire to serve in rural / underserved area, Dislike direct interaction with patients and Influence of Books/ Films were the least influencing factors for deciding to make a choice.

Surprisingly, in our study, unmarried students wanted to have flexible work load. This may be that nowadays nobody wants to have stressful work pressure. Male participants wanted to have secure career scope in future more as compared to their female counterpart. Being the paternal society, the bread winner of the family is male member, so, this might be the reason why male participants want to have secure career. Our study showed that, those who didn't go abroad were influenced by the factor illness of self/family/ friend. This might be because those who stay with the family and friends in their country have more emotional attachment as compared to those who are separated from one's family. Our study also found that those who worked in rural areas were influenced by the friends and seniors while choosing the preferred specialty. This might be that in rural areas few doctors work together and there is more interaction among them so, they know each other very well.

Nearly $87 \%$ participants said that it is good to have career counseling before starting the postgraduate course. This not only helps to choose the better specialty but also saves time of the student they might loss in searching the better institute.

There are some limitations of the study:

1. Foreign students were also included. 
2. This study is done in only one hospital and only single batch was taken.

3. Female students were less in number as compared to male students.

4. This study didn't include the non-clinical specialties except for pathology.

5. All influencing factors were provided in close ended questions which might have not addressed some other unidentified factors.

\section{CONCLUSIONS}

This study also shows that various factors affect the choices for preferred specialty. Policy makers should look at the needs of the nation, and ensure that specialty postgraduate education programs reflect those needs. Most of the students preferred to have career counseling prior to their postgraduate studies. So, Postgraduate career counseling should be started in the respective medical colleges. Frequent seminars should be organized to give the updates about the respective specialties including the doctors working in the rural areas to boost up the interest towards their preferred specialty.

Similar studies should be carried out including more institutions and students making the results strong enough to have effect on the medical education system.

\section{ACKNOWLEDGEMENTS}

Sincere thanks to the Faculty of Department of General Practice and Emergency Medicine, Patan Hospital. Special thanks also goes to Prof. Dr. Bharat Yadav, Prof. Dr. Bruce Hayes, Prof. Dr. Upreet Dhaliwal and all the postgraduate students of years 2011 AD, NAMS

\section{REFERENCES}

1. Bhat S, D'souza L, Fernandez J. Factors influencing the career choices of medical graduates. J Clin Diagn Res. 2012;1-6:61-4.

2. Chew YW, Rajakrishnan S, Low CA, Jayapalan PK, Sreeramareddy CT. Medical students' choice of specialty and factors determining their choice: a cross-sectional questionnaire survey in Melaka-Manipal Medical College, Malaysia. Bioscience trends. 2011;5(2):69-76.

3. Rehman A, Rehman T, Shaikh MA, Yasmin H, Asif A, Kafil H. Pakistani medical students' specialty preference and the influencing factors. J Pak Med Assoc. 2011 Jul;61(7):713-8.

4. Saigal P, Takemura Y, Nishiue T, Fetters M. Factors considered by medical students when formulating their specialty preferences in Japan: findings from a qualitative study. BMC Med Educ. 2007;7:31.

5. Mehmood SI, Kumar A, Al-Binali A, Borleffs JC. Specialty preferences: trends and perceptions among Saudi undergraduate medical students. Med Teach. 2012;34 Suppl 1:S51-60.

6. Butterworth K, Hayes B, Neupane B. Retention of general practitioners in rural Nepal: A qualitative study. Aust J Rural Health. 2008 Jul;16(4):201-6.

7. Lamichhane J. Dilemma of medical graduates in Nepal. Journal of Nepal Health Research Council. 2010 Oct;8(2):116-9.

8. Zimmerman M, Shakya R, Pokhrel BM, Eyal N, Rijal BP, Shrestha RN, Sayami A. Medical students' characteristics as predictors of career practice location: retrospective cohort study tracking graduates of Nepal's first medical college. BMJ. 2012 Aug 13;345:e4826.

9. Wright B, Scott I, Woloschuk W, Brenneis F, Bradley J. Career choice of new medical students at three Canadian universities: Family medicine versus specialty medicine. CMAJ : Canadian Medical Association journal. 2004(170):1920-4.
10. Rosenblatt RA, Andrilla CH. The impact of U.S. medical students' debt on their choice of primary care careers: An analysis of data from the 2002 medical school graduation questionnaire. Academic medicine : journal of the Association of American Medical Colleges. 2005(80):815-9.

11. Dyrbye LN, Eacker AM, Harper W, Power DV, Massie FS, Jr., Satele D, et al. Distress and empathy do not drive changes in specialty preference among US medical students. Med Teach. 2012;34(2):e116-22.

12. Hayes B, Shakya R. Career choices and what influences Nepali medical students and young doctors: a cross-sectional study. Human Resources for Health. 2013;11(1):5.

13. Kumar R, Dhaliwal U. Career choices of undergraduate medical students. The National medical journal of India. 2011 May-Jun;24(3):166-9.

14. Zarkovic A, Child S, G. N. Career choices of New Zealand junior doctors. The New Zealand medical journal. 2006;119(1229).

15. Aslam M, Ali A, Taj T, Badar N, Mirza W, Ammar A, et al. Specialty choices of medical students and house officers in Karachi, Pakistan. Eastern Mediterranean health journal. 2011 Jan;17(1):74-9.

16. Bittaye M, Odukogbe A-TA, Nyan O, Jallow B, Omigbodun A. Medical students' choices of specialty in The Gambia: the need for career counseling. BMC Med Educ. 2012;12(1):72.

17. Huntington I, Shrestha S, Reich N, Hagopian A. Career intentions of medical students in the setting of Nepal's rapidly expanding private medical education system. Health Policy and Plan. 2012;27:417-28.

18. National Academy of Medical Sciences, Bir Hospital. http:// nams.org.np/bir-hospital. 2014. 
19. Dikici MF, Yaris F, Topsever P, Tuncay Muge F, Gurel FS, Cubukcu M, Gorpelioglu S. Factors affecting choice of specialty among first-year medical students of four universities in different regions of Turkey. Croat Med J. 2008; 49:415-420.

20. Dorsey ER, Jarjoura D, Rutecki GW. Influence of controllable lifestyle on recent trends in specialty choice by US medical students. JAMA. 2003; 290:1173-1178.

21. Paik JC, Howard G, Lorenz RG. Postgraduate choices of graduates from medical scientist training programs, 2004-2008. JAMA. 302:1271-3.

22. Fukuda Y, Harada T. Gender differences in specialty preference and mismatch with real needs in Japanese medical students. BMC Med Educ. 2010; 10:15.

23. Newton DA, Grayson MS. Trends in career choice by US medical school graduates. JAMA. 2003; 290:1179-82.

24. Dikici MF, Yaris F, Topsever P, Tuncay Muge F, Gurel FS, Cubukcu M, Gorpelioglu S. Factors affecting medical students in formulating their specialty preferences in Jordan. BMC Med Educ. 2008; 8:32.
25. Mariolis A, Mihas C, Alevizos A, Gizlis V, Mariolis T, Marayiannis K, Tountas Y, Stefanadis C, Philalithis A, Creatsas G. General Practice as a career choice among undergraduate medical students in Greece. BMC Med Educ. 2007; 7:15.

26. Jeffe DB, Whelan AJ, Andriole DA. Primary care specilaty choices of United States medical graduates, 1996-2006. Academic medicine : journal of the Association of American Medical Colleges. 2010 Jun;85(6):947-58.

27. Pawełczyk A, Pawełczyk T, Bielecki J. Determinants of primary care specialty choice. Pol Merkur Lekarski. 2007 Mar;22(129):233-8.

28. Hauer KE, Durning SJ, Kernan WN, Fagan MJ, Mintz M, O'Sullivan PS, et al. Factors associated with medical students' career choices regarding internal medicine. JAMA. 2008 Sep 10;300(10):1154-64.

29. Chang PY, Hung CY, Wang KI, Huang YH, Chang KJ. Factors influencing medical students' choice of specialty. J Formos Med Assoc. 2006 Jun;105(6):489-96. 